\title{
Proton-Stabilized Photochemically Reversible E/Z Isomerization of Spiropyrans
}

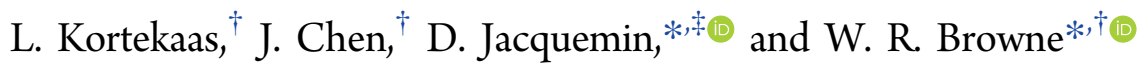 \\ ${ }^{\dagger}$ Molecular Inorganic Chemistry, Stratingh Institute for Chemistry, Faculty of Mathematics and Natural Sciences, University of \\ Groningen, Nijenborgh 4, 9747AG Groningen, The Netherlands \\ ${ }^{\ddagger}$ Chimie Et Interdisciplinarité, Synthèse, Analyse, Modélisation (CEISAM), UMR CNRS no. 6230, Université de Nantes, BP 92208, \\ 2, Rue de la Houssinière, 44322 Nantes Cedex 3, France
}

\section{Supporting Information}

ABSTRACT: Spiropyrans undergo $\mathrm{C}_{\text {spiro }}-\mathrm{O}$ bond breaking to their ring-open protonated E-merocyanine form upon protonation and irradiation via an intermediate protonated $Z$ merocyanine isomer. We show that the extent of acid-induced ring opening is controlled by matching both the concentration and strength of the acid used and with strong acids full ring opening to the $Z$-merocyanine isomer occurs spontaneously allowing its characterization by ${ }^{1} \mathrm{H}$ NMR spectroscopy as well as UV/vis spectroscopy, and reversible switching between $Z$ / E-isomerization by irradiation with UV and visible light. Under sufficiently acidic conditions, both $E$ - and $Z$-isomers are thermally stable. Judicious choice of acid such that its $\mathrm{p} K_{\mathrm{a}}$ lies between that of the $E$ - and $Z$-merocyanine forms enables

thermally stable switching between spiropyran and $E$-merocyanine forms and hence $\mathrm{pH}$ gating between thermally irreversible and reversible photochromic switching.

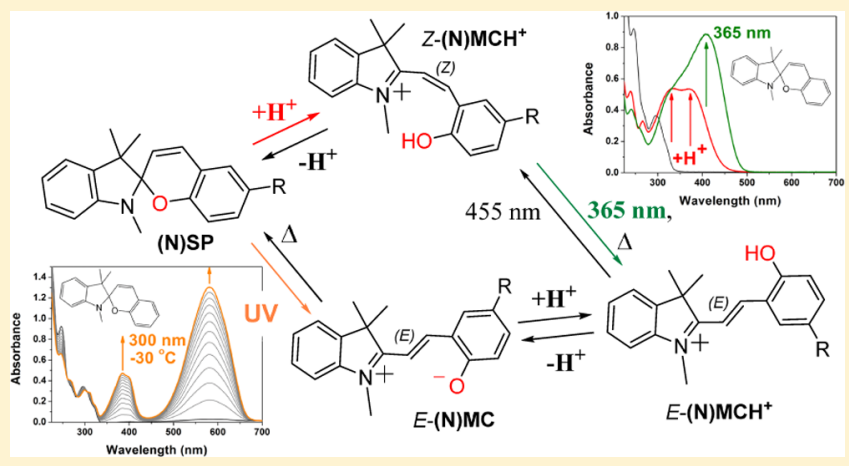

\section{INTRODUCTION}

Smart systems built from molecular switches ${ }^{1}$ that respond to external triggers, such as light, ${ }^{2}$ electricity, ${ }^{3}$ heat, ${ }^{4,5}$ sound, ${ }^{6-8}$ and $\mathrm{pH},{ }^{9}$ through changes in molecular properties (color, polarity, shape, conductivity, reactivity, etc.) are highly desirable due to the possibility to tune these physical responses through structural (synthetic) modification. ${ }^{10}$ Building such molecular switches into materials can impart responsiveness at the macroscopic level, often amplifying the changes in physical properties ranging from sensing ${ }^{11}$ and surface properties ${ }^{12}$ to luminescence ${ }^{13,14}$ and electrochromism. ${ }^{15,16}$ Photochromes, including dithienylethenes, ${ }^{17,18}$ azobenzenes, ${ }^{19,20}$ and spiropyrans, ${ }^{21}$ are among the most widely applied, due to their modularity and flexibility toward modification and the possibility to combine them with other responsive units, e.g., multiphotochromes. ${ }^{22}$ The combination of synthetic versatility, and the thermo- and acidochromism, shown by spiropyrans, in addition to their wellknown photochromism reported first in $1952,{ }^{23}$ has made this class among the most important in applications in smart materials and systems to date.

The photochromism of spiropyrans arises from a light driven interconversion between a "ring-closed" spiropyran (SP) structure and the zwitterionic "ring-open" merocyanine (MC) state, in which the $\mathrm{C}-\mathrm{O}$ bond of the spiro motif is cleaved, and is stabilized by an accompanying $Z / E$-isomerization around the spiro- and pyran-bridging double bond (Scheme 1). The merocyanine "open form" can exist as any of several distinct isomers, denoted commonly by reference to the cis/trans orientation around each of the three bonds starting at the $\mathrm{C}_{\text {spiro }}-$ $\mathrm{C}$ bond, indicated in Scheme 1 by $\alpha, \beta$, and $\gamma$. The preferred conformations and the complex photochromic pathways for several (neutral) spiropyrans have been studied using various $a b$ initio models. ${ }^{24-29}$ The orientation of the $\beta$-bond affects the thermal stability of the merocyanine with regard to reversion to the spiropyran form. Although several colored isomers have been observed at cryogenic temperatures, ${ }^{30}$ the low thermal stability of the cis- $\beta$ configurations (referred to as the $Z$-isomer) means that only the more stable trans- $\beta$ configurations (E-isomer) are observed at ambient temperatures. ${ }^{31}$ Indeed, the TTC form, specifically, was shown by Ernsting and co-workers to be the thermally most stable isomer. ${ }^{32}$

Protonation of the phenol moiety of the merocyanine form impacts the chemistry of spiropyrans and indeed acidochromism has been reported for several spiropyran structures whereby addition of acid results in thermally induced conversion to the protonated merocyanine form $\left(\mathbf{M C H}^{+}\right) .{ }^{33-46}$, However, the mechanism and nature of the intermediate species formed throughout these reports are not consistent, and several conflicting mechanistic scenarios have been proposed to date.

Received: April 13, 2018

Revised: May 18, 2018

Published: May 30, 2018 
Scheme 1. Structures and Photochromism of the Colorless Spiropyran (SP) and Nitrospiropyran (NSP) ${ }^{a}$

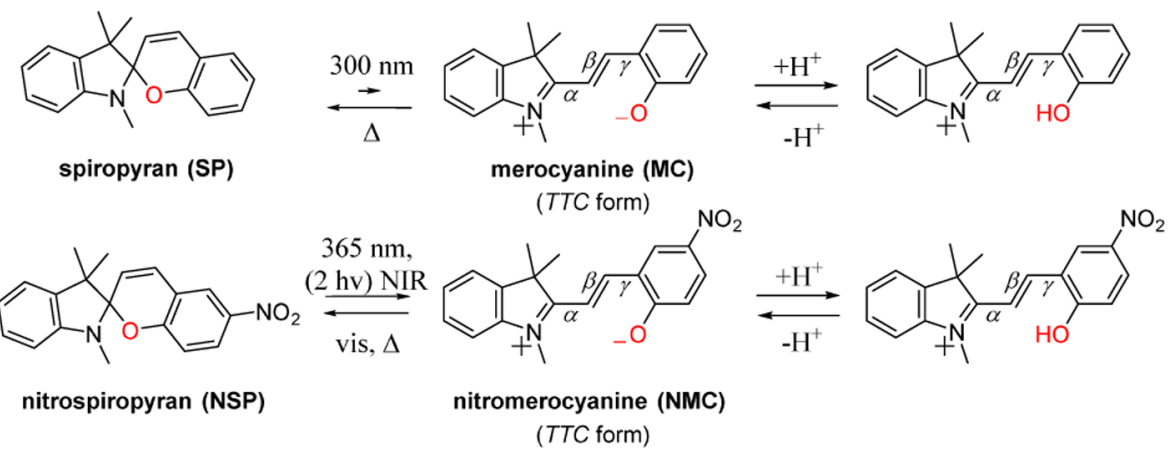

${ }^{a}$ Photoinduced ring-opening can lead to any of eight distinct isomers differing in conformation, cis (C) and trans (T), around the $\alpha, \beta$, and $\gamma$ bonds. Protonation of the colored merocyanine form inhibits thermally induced reformation of the spiro form (ring closing).

Scheme 2. pH-Gated Photochromism of the Colorless Spiropyran (SP) ${ }^{a}$

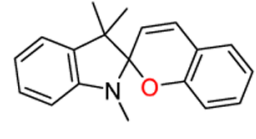

spiropyran (SP)

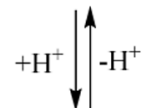

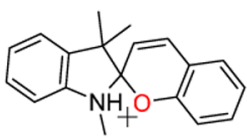

spiropyran $\left(\mathrm{SPH}^{+}\right)$ not observed

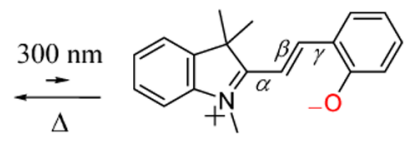

E-merocyanine (MC) (TTC form)

$365 \mathrm{~nm}$

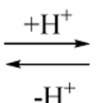

$-\mathrm{H}^{+}$

E-merocyanineH ${ }^{+}\left(\mathrm{MCH}^{+}\right)$

(TTC form)

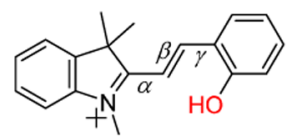
$455 \mathrm{~nm}$

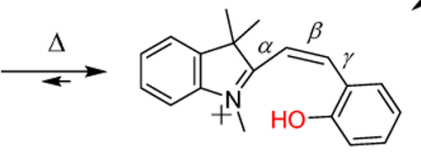

Z-merocyanine- $\mathrm{H}^{+}\left(\mathrm{MCH}^{+}\right)$ (CCC form)

${ }^{a}$ Protonation of SP results in spontaneous ring opening to the Z-merocyanine $\left(Z-\mathbf{M C H}^{+}\right)$. UV irradiation to the thermally stable $E$-merocyanine $(E$ $\mathbf{M C H}^{+}$) is reversed by visible irradiation.

Both Fissi et al. ${ }^{45}$ and Woityk et al., ${ }^{33}$ for example, proposed that a rapid equilibrium between the nonprotonated and $\mathrm{N}$ protonated spiropyran is established in the presence of trifluoroacetic acid, lying in favor of the protonated $E$ merocyanine form. The immediate conversion of the protonated E-merocyanine form upon protonation of a spiropyran impregnated poly(dimethylsiloxane) polymer films was noted by Nam and co-workers also, but with subsequent thermal reversion back to the spiropyran form. ${ }^{46}$ Later Genovese et al. reported that reversion to the ring-closed form could be induced by irradiation with visible light also. ${ }^{34}$ Remón et al., on the other hand, proposed that, in aqueous media, $\mathrm{N}$-protonation only occurs at $\mathrm{pH}$ below 0.5 , and that the only protonated species present is the ring-open merocyanine form, which is in thermal equilibrium with the nonprotonated closed form. ${ }^{36}$ Later, Schmidt et al. noted the formation of the protonated Emerocyanine in ethanol upon addition of trifluoroacetic acid. ${ }^{37}$ Collectively, these reports indicate that ring opening to the stable protonated E-merocyanine occurs upon protonation. However, over two decades ago, Zhou and co-workers reported a species " $\mathrm{Y}$ " while investigating the $\mathrm{pH}$ dependence of the negative photochromism of a $6^{\prime}, 8^{\prime}$-dinitrospiropyran, for which the merocyanine form is most stable even when unprotonated. ${ }^{43}$ Species $\mathrm{Y}$ was assigned to the protonated form of species " $\mathrm{X}$ ", a transient spiropyran species, which has a broken $\mathrm{C}_{\text {spiro }}-\mathrm{O}$ bond and a geometry intermediate to the perpendicular spiro and the planar merocyanine form, and a rapid equilibrium is established between species $\mathrm{Y}$ and the spiro form under sufficiently acidic conditions was established. In the same period, Roxburgh et al. reported the trifluoroacetic acid-induced thermal ring-opening of spiropyrans to their protonated $E$-isomer, which was proposed to be via either the unprotonated or protonated $Z$ form. ${ }^{44}$ The proposed intermediacy of the protonated $Z$ form was supported by Shiozaki subsequently, who proposed that protonation of spiropyran in ethanol with sulfuric acid, a stronger acid than the trifluoroacetic acid, generated the $Z$-merocyanine form, which could not only undergo subsequent thermal but also photochemical $Z / E$-isomerization (Scheme 2). ${ }^{38}$ Shiozaki's interpretation of the changes observed by UV/vis absorption spectroscopy was supported by theoretical studies and is analogous to the acid-induced ring opening ( $\mathrm{C}-\mathrm{O}$ bond cleavage) observed for the related photochromic spirooxazines. ${ }^{47}$ The formation of the $\mathrm{Z}-\mathbf{M C H}^{+}$form has been proposed elsewhere as well ${ }^{48}$ and has been reported in gas-phase studies. ${ }^{49}$

Here, we show through a combination of spectroscopy and theory that the observed $\mathrm{pH}$-induced switching of both spiropyrans (SP) and nitrospiropyrans (NSP) in solution can be rapid and complete (Scheme 2) but is highly dependent on acid strength in nonaqueous solvents. The extent of reaction with acids follows the order of $\mathrm{p} K_{\mathrm{a}}$ values reported, including the intermediate $\mathrm{pK}$ of $\mathrm{HNO}_{3}$ in the middle, for which an excess amount is required to generate the desired response. ${ }^{50-52}$ 
Furthermore, we show unambiguously that the initial step is cleavage of the $\mathrm{C}-\mathrm{O}$ bond to form a relatively stable $\mathrm{Z}$-isomer of the merocyanine that undergoes thermal as well as photochemically induced $Z / E$-isomerization to the more stable $E$-form. Overall, we show that fully reversible isomerization is retained upon acid/base switching provided that the acid used is stronger than the phenol moiety in at least the E-isomer. The demonstration of $\mathrm{pH}$-induced switching between spiro and $\mathrm{Z}$ merocyanine forms as well as photochemical $E / Z$ switching opens new opportunities in the application of spiropyrans as molecular switches. It is especially relevant in applications where large local changes in $\mathrm{pH}$ can occur such as at electrodes, e.g., during cyclic voltammetry, ${ }^{53,54}$ which can affect the observed photochemistry profoundly.

It is notable that in most earlier studies of the $\mathrm{pH}$ dependence of spiropyrans, triflouroacetic acid, ${ }^{33-35,37,39,40}$ as well as $\mathrm{HCl}^{21,36,41,42}$ were the acids of choice employed. Notably, however, in studying $\mathrm{pH}$-gated spiropyran photochromism, Shiozaki employed sulfuric acid. ${ }^{38}$ Here, we show that the choice of acid is crucial for fully understanding the acido-photochromism of spiropyrans. We show that addition of acid to SP and NSP induces a bathochromic shift, the extent of which is dependent on the strength of the acid used. With relatively weak acids, such as trifluoroacetic and $\mathrm{HCl}$ acid, in acetonitrile, acidochromism in SP is weak with only a minor bathochromic shift upon UV irradiation. For NSP, the changes are even less apparent due to its already red-shifted absorption induced by the electron-withdrawing nitro group, which rationalizes why the acidochromism of the spiro form has thus far gone essentially unnoticed. We show here that with stronger acids, protonationinduced changes are clear for both SP and NSP and that both show $\mathrm{pH}$-gated photochromism to the protonated merocyanine forms.

Spontaneous ring opening to the $Z-\mathbf{M C H}^{+} / Z-\mathbf{N M C H}^{+}$states is observed upon addition of strong acid, with subsequent reversible photoinduced isomerization to the $E-\mathrm{MCH}^{+} / E$ $\mathrm{NMCH}^{+}$states. The higher acidity of the protonated $Z$ merocyanine form is demonstrated by adding an acid with a $\mathrm{p} K_{\mathrm{a}}$ intermediate of those of $\mathrm{Z}-\mathbf{M C H}^{+}$and $E-\mathbf{M C H}^{+}$, enabling direct photochemical switching between the SP and thermally stable $E-\mathbf{M C H}^{+}$form at room temperature. Understanding the acid/base switching of spiropyrans and the requirement for matching of the $\mathrm{p} K_{\mathrm{a}}$ of the acid with that of the merocyanine forms, allows for stable access of a total of four photochromic states and opens up a wide range of possibilities for applications as functional units. Finally, although only the spiropyran form is thermally stable at room temperature in the absence of acid and addition of acid induces spontaneous ring opening to the $Z$ $\mathbf{M C H}^{+}$and $E-\mathbf{M C H}^{+}$forms, by using an acid with a $\mathrm{pK}$ a between that of the $Z$ - and E-merocyanine isomers, reversible photochemical switching between thermally stable colorless SP and colored $\mathrm{E}-\mathrm{MCH}^{+}$forms can be achieved at room temperature.

\section{EXPERIMENTAL SECTION}

Materials. NSP and chemicals used for the synthesis of SP were purchased from Aldrich or TCI and were used without further purification. The synthesis of SP is described in the Supporting Information (SI) as well as characterization by NMR spectroscopy $\left({ }^{1} \mathrm{H},{ }^{13} \mathrm{C}\right.$ APT, HSQC, HMBC, COSY, and NOESY) of its protonated $Z$ and $E$ forms generated by trifluoromethanesulfonic acid and phosphoric acid, respectively. High-performance liquid chromatography grade acetonitrile was used for the spectroscopic studies.
Physical Methods. NMR spectra were obtained on a Bruker 600 NMR spectrometer. Chemical shifts $(\delta)$ are reported in parts per million and coupling constants in hertz. Integrations are reported, with multiplicities denoted as: $\mathrm{s}=$ singlet, $\mathrm{d}=$ doublet, $\mathrm{t}$ $=$ triplet, $\mathrm{br}=$ broad singlet, $\mathrm{m}=$ multiplet. Chemical shifts are reported with respect to tetramethylsilane and referenced to residual solvent $\left(\mathrm{CD}_{2} \mathrm{HCN}\right)$ signals. $\mathrm{UV} /$ vis absorption spectra were recorded using an Analytik Jena Specord600 spectrometer. Quantum yields were determined as described in the SI, with calculations concerning the protonated photochromism were performed by determining a photostationary state (PSS) $\left(\lambda_{\text {exc }}\right.$ $365 \mathrm{~nm})$ in the presence of strong acid of $58.9 \% \mathrm{E}_{-} \mathbf{M C H}^{+}$and $68.3 \%$ E-NMCH${ }^{+}$by scaled subtraction. The absorption spectra immediately after protonation to the $Z$-forms and both those resulting from partial deprotonation at the PSS and direct protonation of the merocyanine forms were used for reference. Irradiation was carried out with light-emitting diodes (Thorlabs) at $365 \mathrm{~nm}(4.1 \mathrm{~mW}, \mathrm{M} 365 \mathrm{~F} 1), 455 \mathrm{~nm}(3200 \mathrm{~mW}$, M455L3C5), $565 \mathrm{~nm}(2.0 \mathrm{~mW}, \mathrm{M} 565 \mathrm{~F} 1)$, and $660 \mathrm{~nm}(14.5 \mathrm{~mW}$, M660F1). For details of theoretical calculations see in the SI.

\section{RESULTS AND DISCUSSION}

Acidochromism of SP and NSP with Weak Acids. Although the photochromism of spiropyran (SP) was reported earlier, $^{23}$ the photochromism of $6^{\prime}$-nitrospiropyran (NSP) is much more pronounced ${ }^{55}$ due to resonance stabilization of the phenolate in the ring-open form (see Scheme 1). The merocyanine form of NSP is sufficiently thermally stable for photoswitching to be observed at room temperature $(\Phi=0.03)$, however, the thermal reversion of SP is sufficiently delayed only at $-30^{\circ} \mathrm{C}$ to observe photoswitching to its merocyanine form $(\Phi$ $=0.07$, Figure S1). The acidochromism of NSP and SP has been noted on several occasions, with trifluoroacetic acid in large excess, ${ }^{33-35,37,39,40}$ manifested in a slight bathochromic shift, that is less pronounced for NSP than SP, and in both cases results in only minor amounts of the protonated species (Figure 1). The limited acidochromism of SP and NSP observed with $\mathrm{CF}_{3} \mathrm{CO}_{2} \mathrm{H}$ and $\mathrm{HCl}$ earlier was observed also with excess $\mathrm{CCl}_{3} \mathrm{CO}_{2} \mathrm{H}$ and in the case of NSP with $\mathrm{H}_{3} \mathrm{PO}_{4}$ (Figure S2) also. Irradiation at 365 $\mathrm{nm}$ results in a further slight bathochromic shift, which is reversed by irradiation with visible light. The greater effect on SP than for NSP is consistent with theoretical calculations (Table S1 in the SI).

pH-Gated Photochromism of SP and NSP with Strong Acids. In contrast to the changes observed with acids, such as $\mathrm{CF}_{3} \mathrm{CO}_{2} \mathrm{H}$, addition of near-stoichiometric amounts of strong acids $\left(\mathrm{H}_{2} \mathrm{SO}_{4}, \mathrm{pK}\right.$ $-0.7)^{51}$ to $\mathbf{S P}$ and NSP in acetonitrile resulted in the appearance of a well-defined absorption band assigned to $Z$-isomer of the protonated merocyanine form (Figures 2 and S3), which is unaffected by the addition of further equivalents of acid. A bathochromic shift and increase in absorptivity was induced by subsequent irradiation at $365 \mathrm{~nm}\left(\Phi_{\mathrm{R}=\mathrm{H}}=0.92, \Phi_{\mathrm{R}=\mathrm{NO}_{2}}=0.82\right)$, which is consistent with the observations made and mechanism proposed by Shiozaki, and assigned as due to $Z / E$ isomerisation. ${ }^{38}$ This is also consistent with the theoretical calculations (Table S1 in the SI) that predict a $32 \mathrm{~nm}$ bathochromic shift and a strong increase of the oscillator strength when going from $Z$ $\mathbf{M C H}^{+}$to $E-\mathbf{M C H}^{+}$. Irradiation at $455 \mathrm{~nm}$ results in recovery of the Z-isomer for both NSP (Figure 2) and SP, even under continuous irradiation of the spectrometer (Figure 3 ), and is analogous to the behavior of spirooxazines. ${ }^{47}$ The thermal nature 

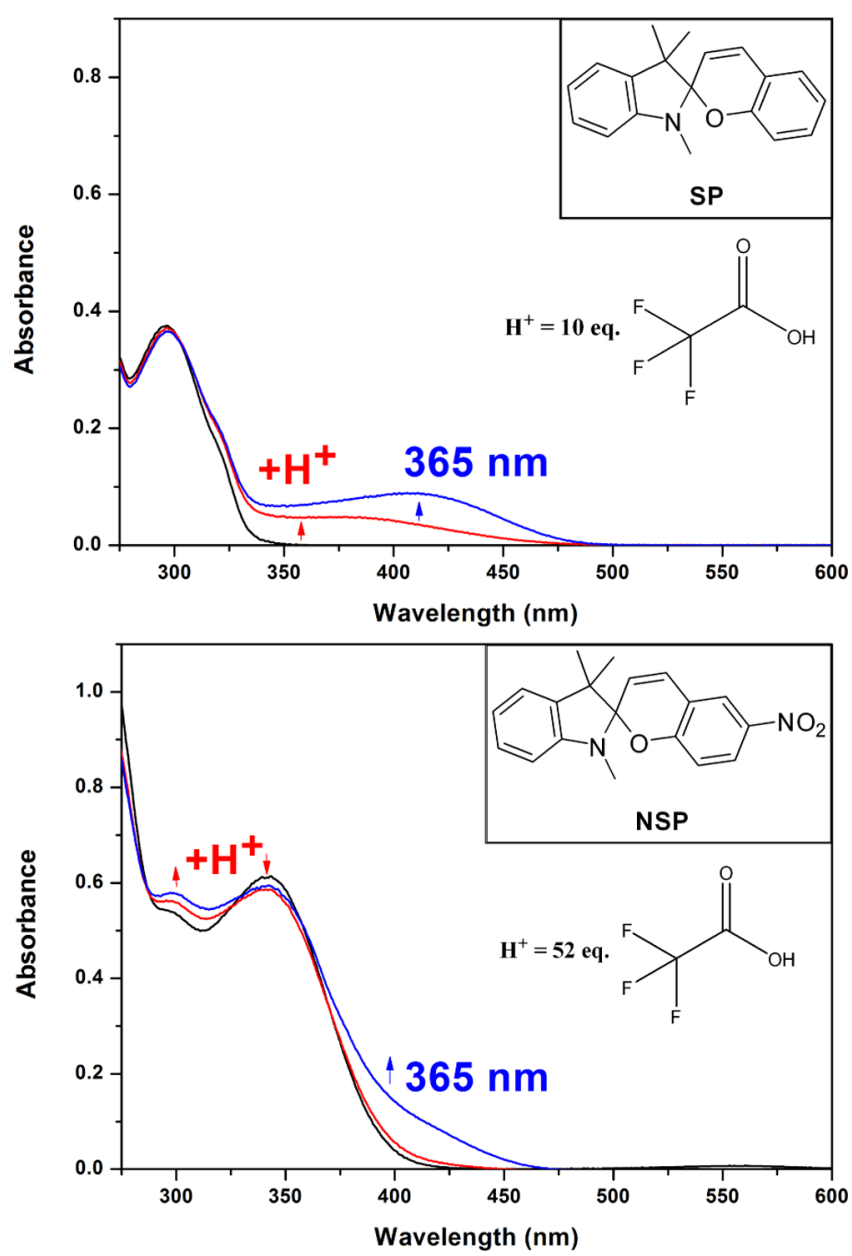

Figure 1. UV/vis absorption spectra of (top) SP and (bottom) NSP (62 $\mu \mathrm{M}$ in acetonitrile, black lines) upon addition of excess $\mathrm{CF}_{3} \mathrm{CO}_{2} \mathrm{H}(10$ and 52 equiv, respectively, red lines) and upon subsequent irradiation at $365 \mathrm{~nm}$ (blue lines). Irradiation with visible light recovers the absorption spectrum prior to irradiation at $365 \mathrm{~nm}$.

of the ring opening was confirmed by monitoring absorbance at $375 \mathrm{~nm}$ only (i.e., monochromatic light source) where the SP form does not absorb but the $\mathrm{Z}-\mathrm{MCH}^{+}$form does absorb, before and after addition of acid. The change in absorbance at $375 \mathrm{~nm}$ was immediate and complete with the mixing time.

The red shift that manifests $Z$ to $E$-isomerization is ascribed to the increase in electronic delocalization that accompanies increased planarity. Indeed, the maximum visible absorption of the TTC isomer of the (deprotonated) merocyanine shifts from 550 to $595 \mathrm{~nm}$ in the TTT isomer (Scheme 1). ${ }^{56,57}$ The protonated $E$-merocyanines are also obtained by addition of 1 equiv of a (strong) acid to E-MC and E-NMC formed by irradiation of SP and NSP at $-30{ }^{\circ} \mathrm{C}$ (to limit thermal reversion, Figures S4 and 4, respectively). Subsequent irradiation at $365 \mathrm{~nm}$ re-establishes the PSS obtained with acid (vide supra) with reversion to the $Z$-isomers upon irradiation at $455 \mathrm{~nm}$.

The acid/base dependence of the photochemistry of both spiropyrans is summarized in Schemes 3 and 4. The data presented here contradict earlier proposals that irradiation of the protonated E-merocyanine leads to the formation of the spiropyran form, ${ }^{33,34,36,46,58}$ based on the loss of visible absorption (i.e., decoloration). Instead, it is the protonated $Z$ merocyanine that was obtained. Indeed, this is the case that is
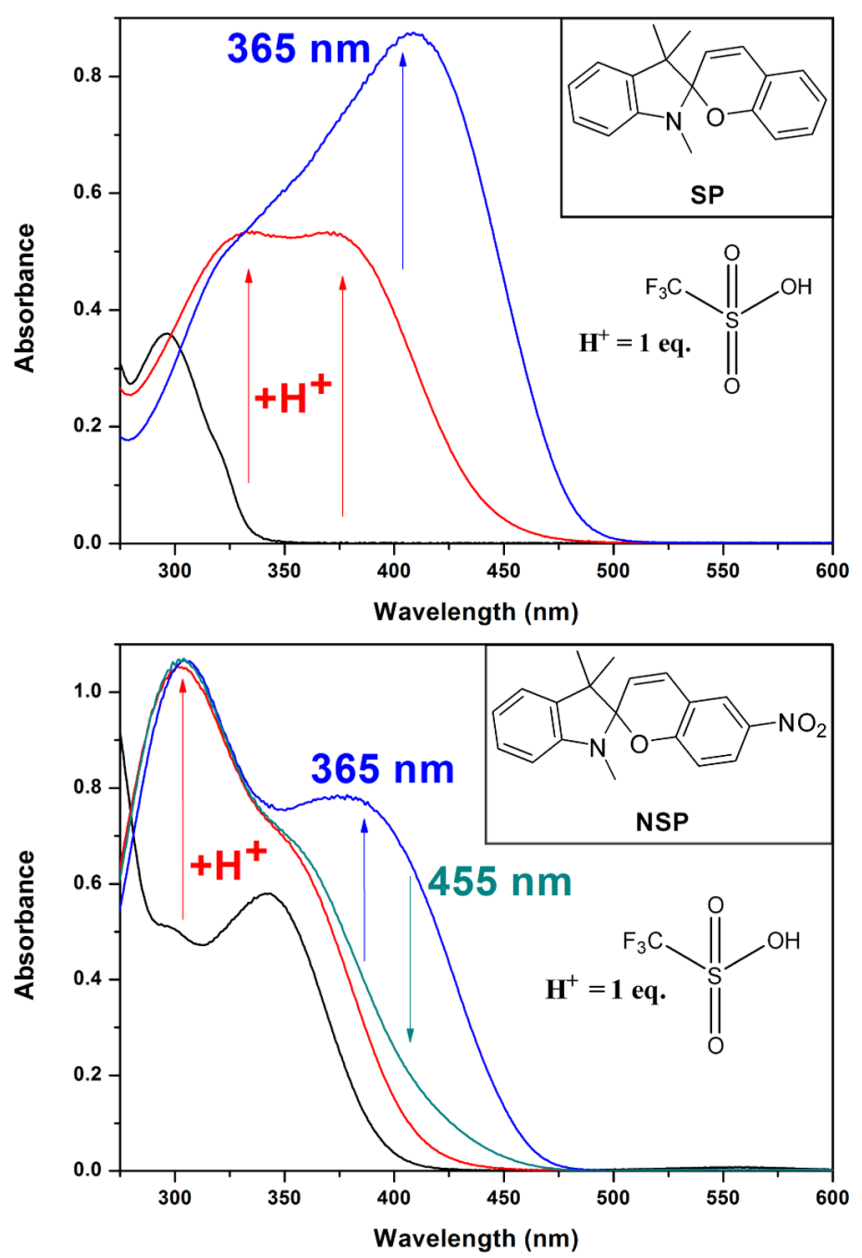

Figure 2. UV/vis absorption spectra of (top) SP and (bottom) NSP (62 $\mu \mathrm{M}$ in acetonitrile, black lines) upon addition of 1 equiv $\mathrm{CF}_{3} \mathrm{SO}_{3} \mathrm{H}$ (red lines). Irradiation at $365 \mathrm{~nm}$ induces a red shift to $420 \mathrm{~nm}$ (blue lines), which is reversed by irradiation at $455 \mathrm{~nm}$ (for $E-\mathbf{M C H}^{+}$to $\mathrm{Z}-\mathbf{M C H}^{+}$see Figure 3).

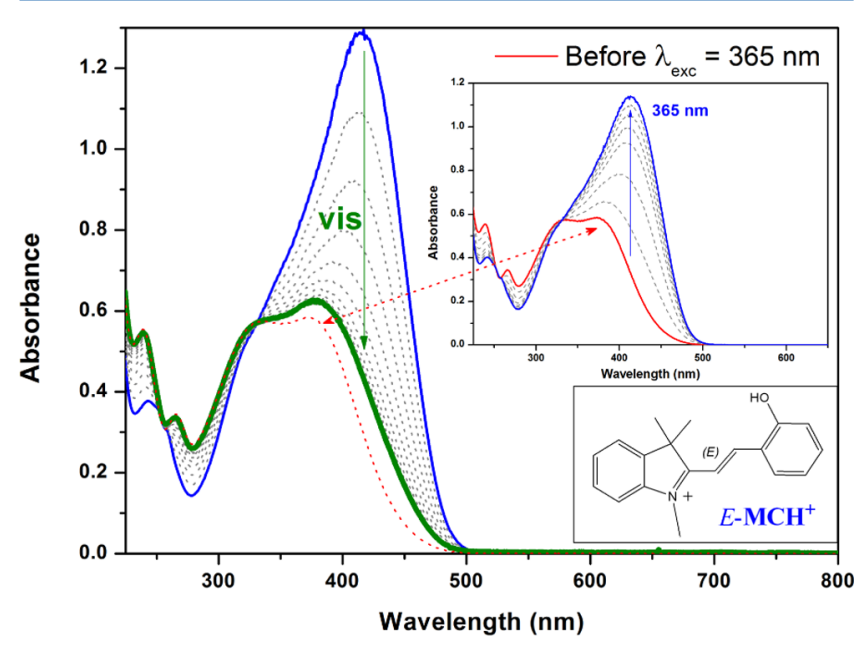

Figure 3. UV/vis absorption of the $E-\mathbf{M C H}^{+}$form (blue line, generated by irradiation at $365 \mathrm{~nm}$, inset) over time, showing near complete reversion to the initial $\mathrm{Z}-\mathrm{MCH}^{+}$form upon continuous visible light irradiation (by the spectrometer, spectra at $100 \mathrm{~s}$ intervals, whereas no change in absorbance was observed over $200 \mathrm{~s}$ in the dark).

apparent in the blue shifted shoulder due to the $Z-(\mathbf{N}) \mathbf{M C H}^{+}$ form in spectra reported earlier. ${ }^{37}$ 


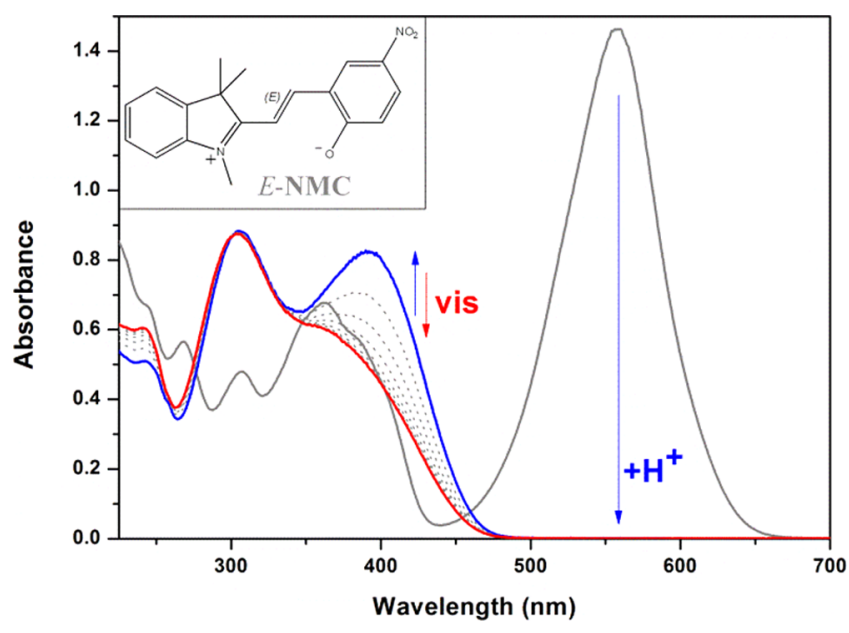

Figure 4. Low temperature UV/vis absorption spectra of E-NSP and of $E$-NMC generated at $-30^{\circ} \mathrm{C}$ by irradiation at $365 \mathrm{~nm}$ (gray solid line, initial concentration of NSP $52 \mu \mathrm{M}$ ). Addition of 1.5 equiv of $\mathrm{CF}_{3} \mathrm{SO}_{3} \mathrm{H}$ leads to formation of $E-\mathrm{NMCH}^{+}$(blue solid line) with reversion to a PSS upon irradiation by the light source of the UV/vis spectrometer (red solid line).

Scheme 3. pH-Gated Photochromism of Spiropyrans and Nitrospiropyrans, in Absence and Presence of Strong Acids

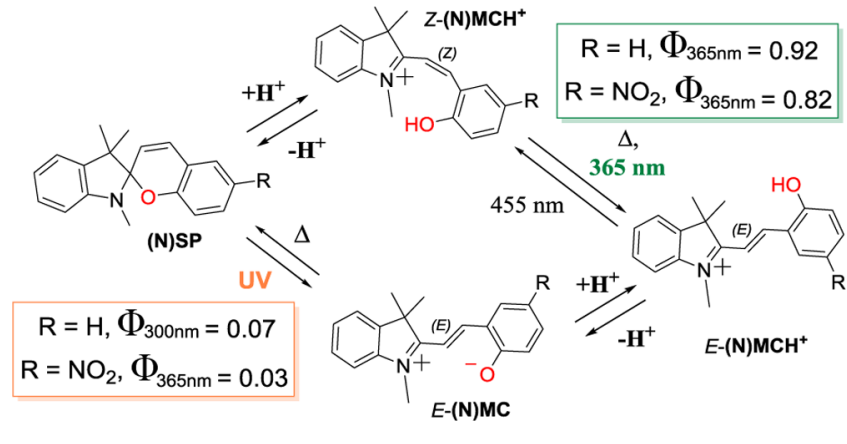

Although deprotonation of $\mathbf{M C H}^{+}$at the photostationary state $\left(\mathrm{PSS}_{365 \mathrm{~nm}}\right)$ results in full recovery of the absorption spectrum of the ring-closed SP and NSP forms, when base is added stepwise substoichiometrically, the conversion of the $Z$-isomer is observed prior to that of the $E$-isomer (Figure S5). The order of recovery is consistent with the $\mathrm{p} K_{\mathrm{a}}$ of the $Z$-isomer being less than that of the $E$-isomer, which is expected considering the contribution of ring closing to the acid/base equilibrium. Furthermore, at $-30{ }^{\circ} \mathrm{C}$, a temperature, at which the E-MC isomers are thermally stable, the visible absorption of the $\mathrm{MC}$ form does not appear until the sufficient base has been added to deprotonate all of the $\mathrm{Z}-\mathbf{M C H}^{+}$ present (Figure S6).

Calculated Energies and Barriers for Ring Opening of SP and NSP. The energies of the observed isomers were calculated using a density functional theory known to be suited for spiropyrans, as detailed in the SI. ${ }^{41}$ The calculated energies of the unprotonated spiropyran forms relative to their merocyanine isomers are fully consistent with experimental data; i.e., that the ring-open form is thermally accessible from the NSP form. Interestingly, a comparison between the computed Raman spectra with those measured experimentally for the nonprotonated SP and NSP forms (Figures S7 and S10) as well as for the protonated $\mathrm{Z}-\mathbf{M C H}^{+}$and $E-\mathbf{M C H}^{+}$show a good qualitative match, which supports that the selected level of theory is well suited for our purposes.
Scheme 4. Computed Free-Energy Profiles for the Optimized Lowest Energy Conformers ${ }^{a, b}$
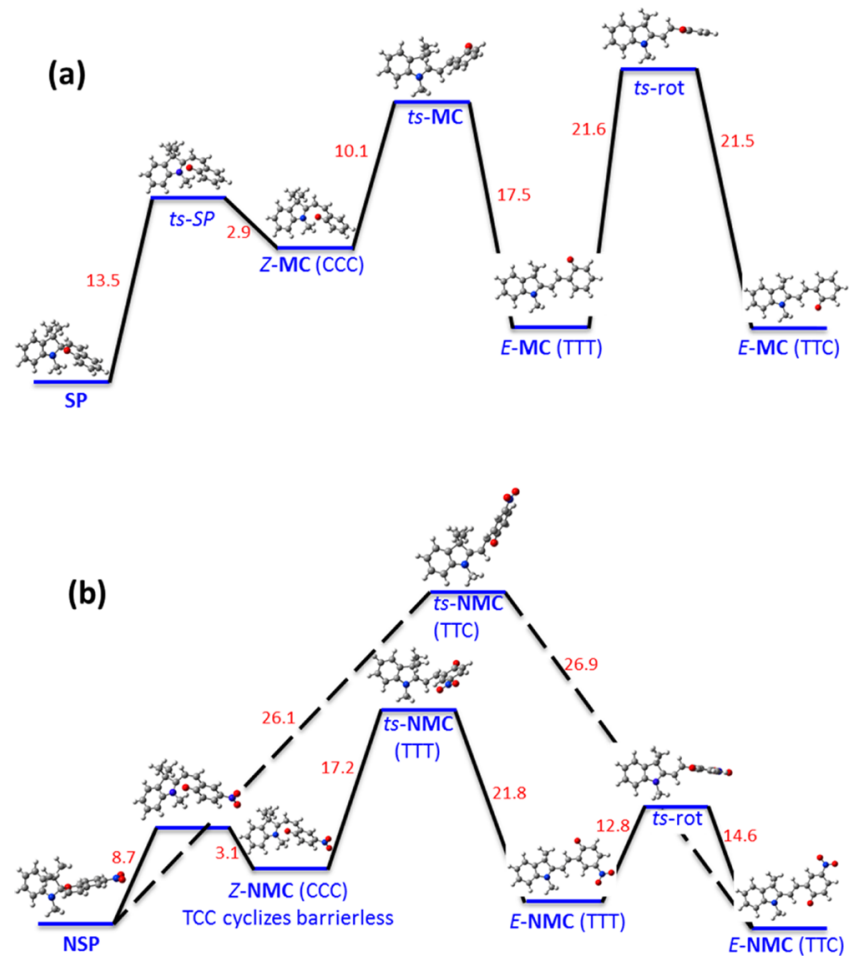

a (a) SP and (b) NSP in the ring-closed spiropyran and ring-open merocyanine forms and the barriers to their interconversiona. ${ }^{b}$ All energy differences given in $\mathrm{kcal} / \mathrm{mol}$.

The lowest energy MC form, the TTT, lies $3.2 \mathrm{kcal} / \mathrm{mol}$ higher than the ring-closed SP form and has a $17.5 \mathrm{kcal} / \mathrm{mol}$ barrier from the $E$ to $Z$ form before undergoing low-barrier ring closing. The lowest energy NMC form, on the other hand, is the TTC conformer, which is $0.8 \mathrm{kcal} / \mathrm{mol}$ lower in energy than the ringclosed form, though closely followed by the TTT $(1.8 \mathrm{kcal} / \mathrm{mol})$. Furthermore, the TTC form, which is the main species observed experimentally also for nitrospiropyrans ${ }^{32,59-61}$ (with in acetonitrile one order of magnitude greater abundance than the TTT form), ${ }^{62}$ has a significantly higher barrier to conversion to the Z-NMC form $(26.9 \mathrm{kcal} / \mathrm{mol}$ for direct conversion, 21.8 $\mathrm{kcal} / \mathrm{mol}$ for conversion through the TTT form). These data are consistent with its observed thermal stability at room temperature. Notably, theory shows that even if the indolinic nitrogen is protonated, as proposed earlier, ${ }^{33,36}$ proton transfer coupled with $\mathrm{C}_{\text {spiro }}-\mathrm{O}$ bond cleavage is barrierless and yields the thermally more stable Z-merocyanine form (Scheme 5).

The barriers are significantly higher than those of the unprotonated forms, ranging from $29.6 \mathrm{kcal} / \mathrm{mol}$ (Scheme 5a) to $39.4 \mathrm{kcal} / \mathrm{mol}$ (Scheme $5 \mathrm{~b}$ ), consistent with their experimentally observed thermal stability. The photochemical interconversion between the $Z$ - and $E$-merocyanine forms thus enables controlled access over two distinct protonated states as shown, through the energetic entrapment of the respective isomers.

Re-enabling Room Temperature Switching of SP. The difference in the $\mathrm{p} K_{\mathrm{a}} \mathrm{s}$ of the $Z$ and $E$-merocyanine isomers additionally opens the possibility to gate the photochromism of SP with $\mathrm{pH}$. In large excess, $\mathrm{H}_{3} \mathrm{PO}_{4}$ induces formation of $\mathrm{Z}$ $\mathbf{M C H}^{+}$(Figure S7), whereas near-stoichiometric amounts have essentially no effect on the absorption spectrum of SP. 
Scheme 5. Computed Free-Energy Profiles for the Optimized Lowest Energy Conformers of the Protonated Forms of (a) SP and (b) NSP $^{a}$
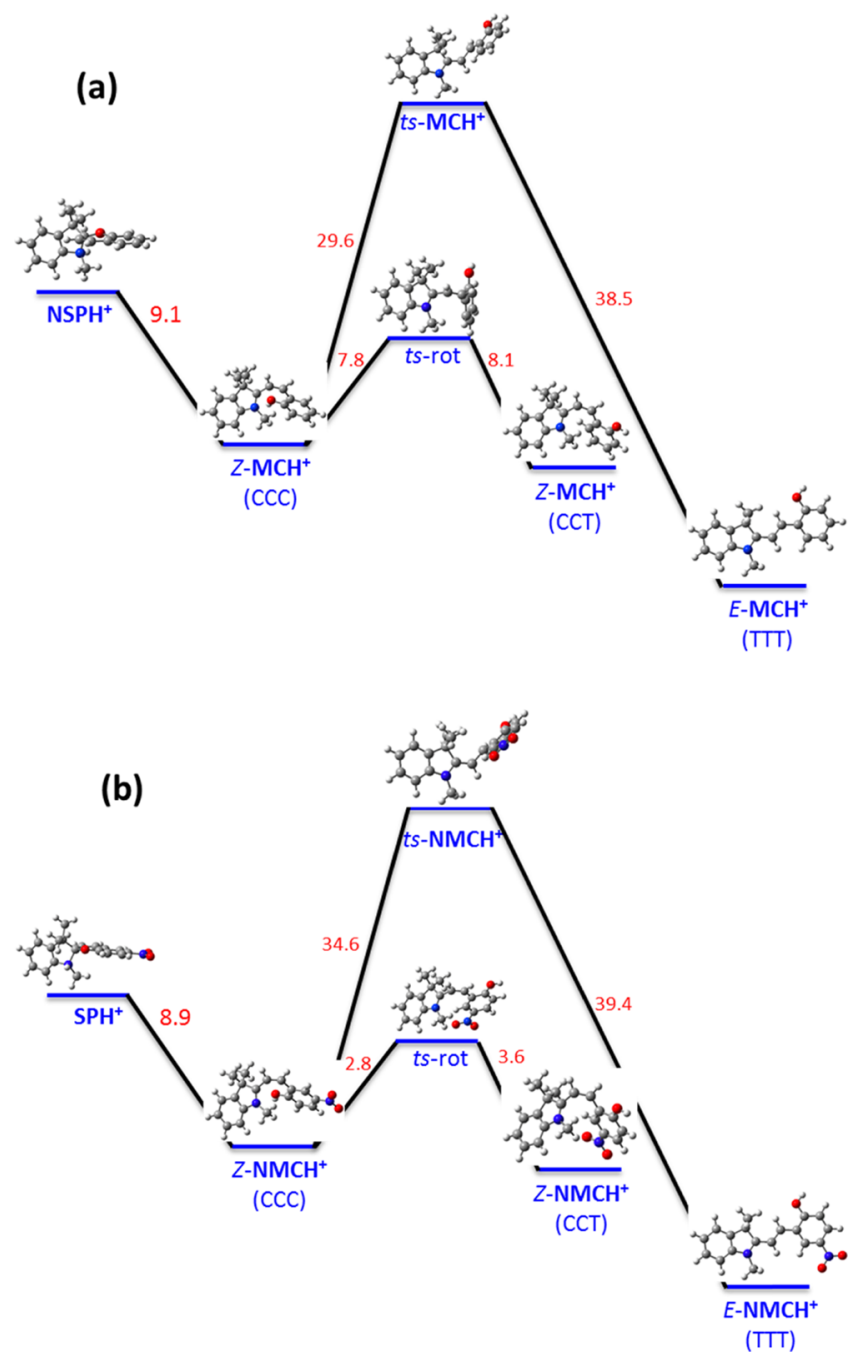

${ }^{a}$ See caption of Scheme 3.

Remarkably, in presence of equimolar phosphoric acid at room temperature solely the $E-\mathbf{M C H}^{+}$isomer is generated both upon irradiation at $300 \mathrm{~nm}$ (Figure 5) and thermally over time (Figure S8), with full recovery to the unprotonated SP form upon subsequent irradiation at $455 \mathrm{~nm}$. This effect is observed because the $\mathrm{pK}$ a $\mathrm{H}_{3} \mathrm{PO}_{4}$ lies between that of the $E$ - and Z-MCH isomers. Any $\mathrm{H}_{2} \mathrm{PO}_{4}{ }^{-}$present will deprotonate $\mathrm{Z}-\mathbf{M C H}^{+}$ spontaneously inducing ring closing, whereas any photogenerated E-MC will undergo protonation by $\mathrm{H}_{3} \mathrm{PO}_{4}$ preventing thermal reversion and thus enables essentially direct photoconversion between SP and $E-\mathbf{M C H}^{+}$forms through the Le Chatelier principle (Scheme 6) despite that SP/E-MC photochromism is thermally inhibited at room temperature. Furthermore, the thermal stability of the $E-\mathbf{M C H}^{+}$formed in the presence of near-stoichiometric amounts of $\mathrm{H}_{3} \mathrm{PO}_{4}$ allows for its characterization by NMR spectroscopy $\left({ }^{1} \mathrm{H},{ }^{13} \mathrm{C}\right.$ APT, HSQC, $\mathrm{HMBC}$, COSY, and NOESY) as well as that of the Z-MCH form generated by addition of $\mathrm{CF}_{3} \mathrm{SO}_{3} \mathrm{H}$ (see the SI).

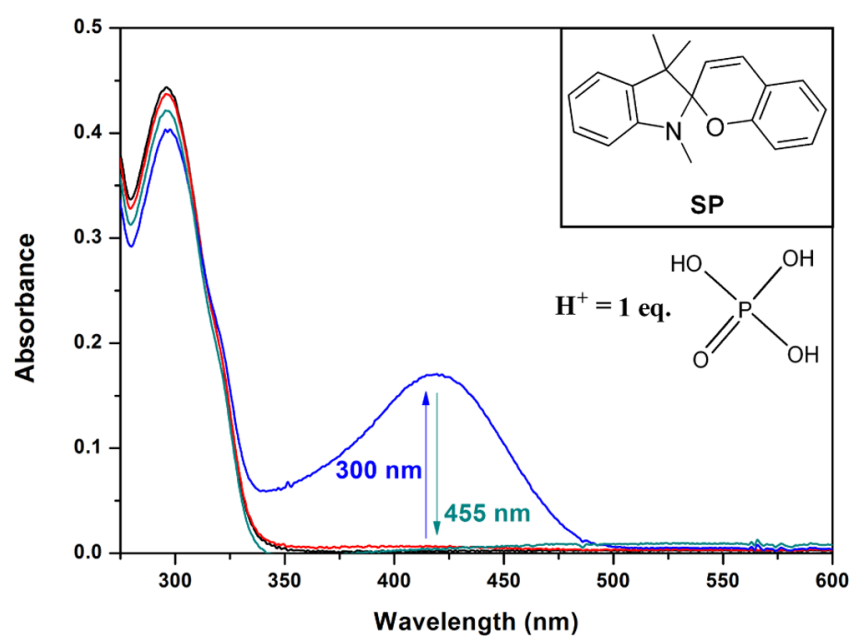

Figure 5. UV/vis absorption spectra of SP (62 $\mu \mathrm{M}$ in acetonitrile, black line) with 1 equiv $\mathrm{H}_{3} \mathrm{PO}_{4}$ (red line) followed by irradiation at $300 \mathrm{~nm}$ (to form $\mathrm{E}-\mathrm{MCH}^{+}$, blue line), whereas irradiation at $455 \mathrm{~nm}$ recovers the SP form.

Scheme 6. Unidirectional Cyclic Interconversion between SP and $\mathrm{E}-\mathrm{MCH}^{+}$upon $\mathrm{pH}$-Gated Photochromism in Near-

Stoichiometric Presence of $\mathrm{H}_{3} \mathrm{PO}_{4}$

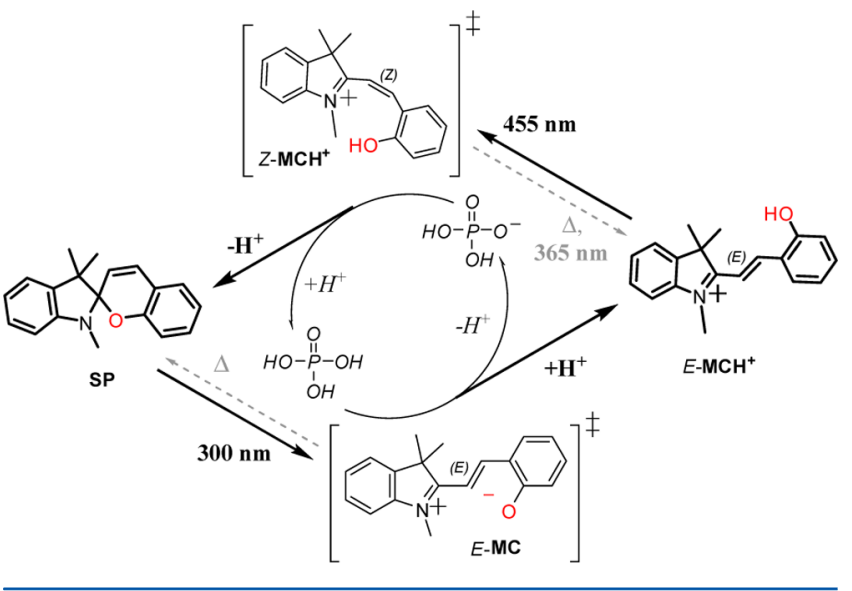

\section{CONCLUSIONS}

In conclusion, we show through a combined experimental and theoretical study that the acidochromism of spiropyrans is highly dependent on the strength of the acid used in aprotic solvents, with acids, such as $\mathrm{CF}_{3} \mathrm{CO}_{2} \mathrm{H}$ and $\mathrm{HCl}$, used typically, being too weak to protonate the $\mathrm{Z}$-(N)MC isomer. Fully $\mathrm{pH}$-gated photochromism of simple spiropyrans is achieved with stronger acids (e.g., $\mathrm{CF}_{3} \mathrm{SO}_{3} \mathrm{H}$ ), manifested in the two-state photoisomerization of $Z-(\mathbf{N}) \mathbf{M C H}^{+} / E-(\mathbf{N}) \mathbf{M C H}^{+}$and together with (N)SP/E-(N)MC photoisomerization, leads to an overall fourstate molecular switching cycle. In retrospect, the reactivity reported in the present study implies that in earlier studies the $Z$ (N) $\mathbf{M C H}^{+}$form may have been observed erroneously assigned as the expected ring-closed spiropyran form. The theoretically computed energies agree with the experimentally observed forms and moreover underline the increased stabilities of the $Z$ - and $E$ isomers through significantly higher thermal barriers than in the deprotonated states. Additionally, in contrast to conclusions drawn earlier regarding the protonation of spiropyrans, ${ }^{33,34,36,37,45,46,48}$ theory suggests that the protonation of the indolinic nitrogen leads to barrierless proton transfer to the 
phenolate. Hence, even if an acid is strong enough to protonate the indolinic nitrogen, spontaneous ring opening to the $Z-(\mathbf{N})$ $\mathbf{M C H}^{+}$form would make such a protonation transient at most. Finally, by selecting an acid such that its $\mathrm{p} K_{\mathrm{a}}$ lies between that of the $Z$ - and $E-\mathbf{M C H}^{+}$isomers (e.g., $\mathrm{H}_{3} \mathrm{PO}_{4}$ in the case of SP), enables gated photochromism and a unidirectional multistate interconversion between spiropyran and merocyanine species at room temperature. The nitro group of NSP is electron withdrawing in comparison with SP and as such stabilizes the merocyanine form both in the deprotonated form and as a leaving group in the ring-opening process. As a counter poise to these effects, however, the nitro group decreases the $\mathrm{p} K_{\mathrm{a}}$ and hence the strength of acid required to achieve thermal ring opening needs therefore to be greater. Overall, however, the nitro group of NSP does not appear to affect the mechanisms involved in comparison with SP.

The $\mathrm{p} K_{\mathrm{a}}$-dependent control of the state of the photochrome opens new opportunities in the application of spiropyrans in photocontrol of $\mathrm{pH}$ and in understanding the influence of local $\mathrm{pH}$ changes (e.g., at surfaces of electrodes) have on spiropyranbased electrochemical devices.

\section{ASSOCIATED CONTENT}

\section{S Supporting Information}

The Supporting Information is available free of charge on the ACS Publications website at DOI: 10.1021/acs.jpcb.8b03528.

Details of synthesis and characterization of SP with NMR spectroscopic characterization $\left({ }^{1} \mathrm{H},{ }^{13} \mathrm{C}\right.$ APT, HSQC, HMBC, COSY, and NOESY) of both $Z-\mathbf{M C H}^{+}$and $E$ $\mathbf{M C H}^{+}$; actinometry; computational studies; experimental and calculated Raman spectra of the SP/NSP forms and $Z$ $\mathbf{M C H}^{+} / Z-\mathbf{N M C H}^{+}$and $E-\mathbf{M C H}^{+} / E-\mathbf{N M C H}^{+}$forms; and additional $\mathrm{UV} /$ vis absorption spectral data (PDF)

\section{AUTHOR INFORMATION}

\section{Corresponding Authors}

*E-mail: denis.jacquemin@univ-nantes.fr (D.J.).

*E-mail: w.r.browne@rug.nl (W.R.B.).

ORCID

D. Jacquemin: 0000-0002-4217-0708

W. R. Browne: 0000-0001-5063-6961

\section{Author Contributions}

All authors have contributed and given approval to the final version of the manuscript.

\section{Funding}

Financial support was provided by The Netherlands Ministry of Education, Culture and Science (Gravity Program 024.001.035 to L.K. and W.R.B.), and Chinese Scholarship Council (J.C.). This work used computational resources of the CCIPL in Nantes and the GENCI-IDRIS.

\section{Notes}

The authors declare no competing financial interest.

\section{ABBREVIATIONS}

SP, 1,3,3-trimethylbenzoindolinopyrylospiropyran; NSP, 6'nitro-1,3,3-trimethylbenzoindolinopyrylospiropyran; $\mathrm{MC}$, 1,3,3-trimethylbenzoindolinopyrylomerocyanine; NMC, 6'nitro-1,3,3-trimethylbenzoindolinopyrylomerocyanine

\section{REFERENCES}

(1) Wang, L.; Li, Q. Photochromism into Nanosystems: Towards Lighting up the Future Nanoworld. Chem. Soc. Rev. 2018, 47, 10441097.

(2) Karimi, M.; Sahandi Zangabad, P.; Baghaee-Ravari, S.; Ghazadeh, M.; Mirshekari, H.; Hamblin, M. R. Smart Nanostructures for Cargo Delivery: Uncaging and Activating by Light. J. Am. Chem. Soc. 2017, 139, 4584-4610.

(3) Luo, Y.; Yu, X. Light and Electrically Responsive Materials Based on Aligned Carbon Nanotubes. Eur. Polym. J. 2016, 82, 290-299.

(4) Zhang, Y.; Li, Y.; Liu, W. Dipole-Dipole and h-Bonding Interactions Significantly Enhance the Multifaceted Mechanical Properties of Thermoresponsive Shape Memory Hydrogels. Adv. Funct. Mater. 2015, 25, 471-480.

(5) Chan, B. Q. Y.; Liow, S. S.; Loh, X. J. Organic-Inorganic Shape Memory Thermoplastic Polyurethane Based on Polycaprolactone and Polydimethylsiloxane. RSC Adv. 2016, 6, 34946-34954.

(6) Naota, T.; Koori, H. Molecules That Assemble by Sound: An Application to the Instant Gelation of Stable Organic Fluids. J. Am. Chem. Soc. 2005, 127, 9324-9325.

(7) Deng, C.; Fang, R.; Guan, Y.; Jiang, J.; Lin, C.; Wang, L. SonicationInduced Self-Assembly of Flexible Tris(Ureidobenzyl)Amine: From Dimeric Aggregates to Supramolecular Gels. Chem. Commun. 2012, 48, 7973.

(8) van Herpt, J. T.; Stuart, M. C. A.; Browne, W. R.; Feringa, B. L. Mechanically Induced Gel Formation. Langmuir 2013, 29, 8763-8767.

(9) Hu, Y.; Lu, C. H.; Guo, W.; Aleman-Garcia, M. A.; Ren, J.; Willner, I. A Shape Memory Acrylamide/DNA Hydrogel Exhibiting Switchable Dual PH-Responsiveness. Adv. Funct. Mater. 2015, 25, 6867-6874.

(10) Kathan, M.; Hecht, S. Photoswitchable Molecules as Key Ingredients to Drive Systems Away from the Global Thermodynamic Minimum. Chem. Soc. Rev. 2017, 46, 5536-5550.

(11) Jones, C. D.; Steed, J. W. Gels with Sense: Supramolecular Materials That Respond to Heat, Light and Sound. Chem. Soc. Rev. 2016, $45,6546-6596$.

(12) Guo, F.; Guo, Z. Inspired Smart Materials with External Stimuli Responsive Wettability: A Review. RSC Adv. 2016, 6, 36623-36641.

(13) Saad, A.; Oms, O.; Dolbecq, A.; Menet, C.; Dessapt, R.; SerierBrault, H.; Allard, E.; Baczko, K.; Mialane, P. A High Fatigue Resistant, Photoswitchable Fluorescent Spiropyran-polyoxometalate-BODIPY Single-Molecule. Chem. Commun. 2015, 51, 16088-16091.

(14) Kortekaas, L.; Lancia, F.; Steen, J. D.; Browne, W. R. Reversible Charge Trapping in Bis-Carbazole-Diimide Redox Polymers with Complete Luminescence Quenching Enabling Nondestructive ReadOut by Resonance Raman Spectroscopy. J. Phys. Chem. C 2017, 121, 14688-14702.

(15) Kortekaas, L.; Ivashenko, O.; Van Herpt, J. T.; Browne, W. R. A Remarkable Multitasking Double Spiropyran: Bidirectional VisibleLight Switching of Polymer-Coated Surfaces with Dual Redox and Proton Gating. J. Am. Chem. Soc. 2016, 138, 1301-1312.

(16) Li, Z.; Zhou, Y.; Peng, L.; Yan, D.; Wei, M. A Switchable Electrochromism and Electrochemiluminescence Bifunctional Sensor Based on the Electro-Triggered Isomerization of Spiropyrane/Layered Double Hydroxides. Chem. Commun. 2017, 53, 8862-8865.

(17) Logtenberg, H.; Browne, W. R. Electrochemistry of Dithienylethenes and Their Application in Electropolymer Modified Photo- and Redox Switchable Surfaces. Org. Biomol. Chem. 2013, 11, 233-243.

(18) Irie, M.; Fukaminato, T.; Matsuda, K.; Kobatake, S. Photochromism of Diarylethene Molecules and Crystals: Memories, Switches, and Actuators. Chem. Rev. 2014, 114, 12174-12277.

(19) Mart, R. J.; Allemann, R. K. Azobenzene Photocontrol of Peptides and Proteins. Chem. Commun. 2016, 52, 12262-12277.

(20) Xia, X.; Yu, H.; Wang, L.; ul-Abdin, Z. Recent Progress in Ferrocene- and Azobenzene-Based Photoelectric Responsive Materials. RSC Adv. 2016, 6, 105296-105316.

(21) Klajn, R. Spiropyran-Based Dynamic Materials. Chem. Soc. Rev. 2014, 43, 148-184. 
(22) Fihey, A.; Perrier, A.; Browne, W. R.; Jacquemin, D. Multiphotochromic Molecular Systems. Chem. Soc. Rev. 2015, 44, 37193759.

(23) Fischer, E.; Hirshberg, Y. Formation of Coloured Forms of Spirans by Low-Temperature Irradiation. J. Chem. Soc 1952, 45224524.

(24) Liu, F.; Morokuma, K. Multiple Pathways for the Primary Step of the Spiropyran Photochromic Reaction: A CASPT2//CASSCF Study. J. Am. Chem. Soc. 2013, 135, 10693-10702.

(25) Prager, S.; Burghardt, I.; Dreuw, A. Ultrafast Cspiro-O Dissociation via a Conical Intersection Drives Spiropyran to Merocyanine Photoswitching. J. Phys. Chem. A 2014, 118, 1339-1349.

(26) Savarese, M.; Raucci, U.; Netti, P. A.; Adamo, C.; Rega, N.; Ciofini, I. A Qualitative Model to Identify Non-Radiative Decay Channels: The Spiropyran as Case Study. Theor. Chem. Acc. 2016, 135, No. 211.

(27) Pomogaev, V. A.; Barachevsky, V. A.; Tuktarov, A. R.; Avramov, P. V.; Artyukhov, V. Y. Inheritance of Photochromic Properties of NitroSubstituted and Halogenated Spiropyrans Containing the Pyrrolidino[60]Fullerene. J. Phys. Chem. A 2018, 122, 505-515.

(28) Mendive-Tapia, D.; Kortekaas, L.; Steen, J. D.; Perrier, A.; Lasorne, B.; Browne, W. R.; Jacquemin, D. Accidental Degeneracy in the Spiropyran Radical Cation: Charge Transfer between Two Orthogonal Rings Inducing Ultra-Efficient Reactivity. Phys. Chem. Chem. Phys. 2016, $18,31244-31253$.

(29) Walter, C.; Ruetzel, S.; Diekmann, M.; Nuernberger, P.; Brixner, T.; Engels, B. Photoisomerization among Ring-Open Merocyanines. II. A Computational Study. J. Chem. Phys. 2014, 140, No. 224311.

(30) Hirshberg, Y.; Fischer, E. Multiple Reversible Color Changes Initiated by Irradiation at Low Temperature. J. Chem. Phys. 1953, 16191620.

(31) Minkin, V. I. Photo-, Thermo-, Solvato-, and Electrochromic Spiroheterocyclic Compounds. Chem. Rev. 2004, 104, 2751-2776.

(32) Ernsting, N. P.; Dick, B.; Arthen-Engeland, T. The Primary Photochemical Reaction Step of Unsubstituted Indolino-Spiropyrans. Pure Appl. Chem. 1990, 62, 1483-1488.

(33) Wojtyk, J. T. C.; Wasey, A.; Xiao, N. N.; Kazmaier, P. M.; Hoz, S.; Yu, C.; Lemieux, R. P.; Buncel, E. Elucidating the Mechanisms of Acidochromic Spiropyran-Merocyanine Interconversion. J. Phys. Chem. A 2007, 111, 2511-2516.

(34) Genovese, M. E.; Athanassiou, A.; Fragouli, D. Photoactivated Acidochromic Elastomeric Films for on Demand Acidic Vapor Sensing. J. Mater. Chem. A 2015, 3, 22441-22447.

(35) Genovese, M. E.; Colusso, E.; Colombo, M.; Martucci, A.; Athanassiou, A.; Fragouli, D. Acidochromic Fibrous Polymer Composites for Rapid Gas Detection. J. Mater. Chem. A 2017, 5, 339-348.

(36) Remón, P.; Li, S. M.; Grotli, M.; Pischel, U.; Andreasson, J. An Acido- and Photochromic Molecular Device That Mimics Triode Action. Chem. Commun. 2016, 52, 4659-4662.

(37) Schmidt, S. B.; Kempe, F.; Brügner, O.; Walter, M.; Sommer, M. Alkyl-Substituted Spiropyrans: Electronic Effects, Model Compounds and Synthesis of Aliphatic Main-Chain Copolymers. Polym. Chem. 2017, 5407-5414.

(38) Shiozaki, H. Molecular Orbital Calculations for Acid Induced Ring Opening Reaction of Spiropyran. Dyes Pigm. 1997, 33, 229-237.

(39) Raymo, F. M.; Giordani, S. Signal Processing at the Molecular Level. J. Am. Chem. Soc. 2001, 123, 4651-4652.

(40) Raymo, F. M.; Giordani, S.; White, A. J. P.; Williams, D. J. Digital Processing with a Three-State Molecular Switch. J. Org. Chem. 2003, 68, $4158-4169$.

(41) Keum, S. R.; Lee, K. B.; Kazmaier, P. M.; Buncel, E. A Novel Method for Measurement of the Merocyanine-Spiropyran Interconversion in Non-Activated 1, 3, 3-Trimethylspiro- (2H-1-Benzopyran-2, 2'Indoline) Derivatives. Tetrahedron Lett. 1994, 35, 1015-1018.

(42) Zhao, Z.; Tian, J. Ultraviolet-visible/Fluorescence Behaviors of a Spiropyran/Polydimethylsiloxane Composite Film under Acid Vapors. J. Appl. Polym. Sci. 2017, 134, No. 45199.
(43) Zhou, J.; Li, Y.; Tang, Y.; Zhao, F.; Song, X.; Li, E. Detailed Investigation on a Negative Photochromic Spiropyran. J. Photochem. Photobiol., A 1995, 90, 117-123.

(44) Roxburgh, C. J.; Sammes, P. G. On the Acid Catalysed Isomerisation of Some Substituted Spirobenzopyrans. Dyes Pigm. 1995, 27, 63-69.

(45) Fissi, A.; Pieroni, O.; Angelini, N.; Lenci, F. Photoresponsive Polypeptides. Photochromic and Conformational Behavior of Spiropyran-Containing Poly-l-Glutamate)s under Acid Conditions. Macromolecules 1999, 32, 7116-7121.

(46) Nam, Y.-S.; Yoo, I.; Yarimaga, O.; Park, I. S.; Park, D.-H.; Song, S.; Kim, J.-M.; Lee, C. W. Photochromic Spiropyran-Embedded PDMS for Highly Sensitive and Tunable Optochemical Gas Sensing. Chem. Commun. 2014, 50, 4251-4254.

(47) Beaujean, P.; Bondu, F.; Plaquet, A.; Garcia-Amorós, J.; Cusido, J.; Raymo, F. M.; Castet, F.; Rodriguez, V.; Champagne, B. Oxazines: A New Class of Second-Order Nonlinear Optical Switches. J. Am. Chem. Soc. 2016, 138, 5052-5062.

(48) Shi, Z.; Peng, P.; Strohecker, D.; Liao, Y. Long-Lived Photoacid Based upon a Photochromic Reaction. J. Am. Chem. Soc. 2011, 133, 14699-14703.

(49) Markworth, P. B.; Adamson, B. D.; Coughlan, N. J. A.; Goerigk, L.; Bieske, E. J. Photoisomerization Action Spectroscopy: Flicking the Protonated Merocyanine-spiropyran Switch in the Gas Phase. Phys. Chem. Chem. Phys. 2015, 17, 25676-25688.

(50) Kütt, A.; Leito, I.; Kaljurand, I.; Sooväli, L.; Vlasov, V. M.; Yagupolskii, L. M.; Koppel, I. A. A Comprehensive Self-Consistent Spectrophotometric Acidity Scale of Neutral Brønsted Acids in Acetonitrile. J. Org. Chem. 2006, 71, 2829-2838.

(51) Kütt, A.; Rodima, T.; Saame, J.; Raamat, E.; Mäemets, V.; Kaljurand, I.; Koppel, I. A.; Garlyauskayte, R. Y.; Yagupolskii, Y. L.; Yagupolskii, L. M.; et al. Equilibrium Acidities of Superacids. J. Org. Chem. 2011, 76, 391-395.

(52) Paenurk, E.; Kaupmees, K.; Himmel, D.; Kütt, A.; Kaljurand, I.; Koppel, I. A.; Krossing, I.; Leito, I. A Unified View to Brønsted Acidity Scales: Do We Need Solvated Protons? Chem. Sci. 2017, 8, 6964-6973.

(53) Kuhn, A. T.; Chan, C. Y. PH Changes at Near-Electrode Surfaces. J. Appl. Electrochem. 1983, 13, 189-207.

(54) Read, T. L.; Bitziou, E.; Joseph, M. B.; Macpherson, J. V. In Situ Control of Local $\mathrm{Ph}$ Using a Boron Doped Diamond Ring Disk Electrode: Optimizing Heavy Metal (Mercury) Detection. Anal. Chem. 2014, 86, 367-371.

(55) Berman, E.; Fox, R. E.; Thomson, F. D. Photochromic Spiropyrans. I. The Effect of Substituents on the Rate of Ring Closure. J. Am. Chem. Soc. 1959, 81, 5605-5608.

(56) Ruetzel, S.; Diekmann, M.; Nuernberger, P.; Walter, C.; Engels, B.; Brixner, T. Photoisomerization among Ring-Open Merocyanines. I. Reaction Dynamics and Wave-Packet Oscillations Induced by Tunable Femtosecond Pulses. J. Chem. Phys. 2014, 140, No. 224310.

(57) Kim, D.; Zhang, Z.; Xu, K. Spectrally Resolved Super-Resolution Microscopy Unveils Multipath Reaction Pathways of Single Spiropyran Molecules. J. Am. Chem. Soc. 2017, 139, 9447-9450.

(58) Ziółkowski, B.; Florea, L.; Theobald, J.; Benito-Lopez, F.; Diamond, D. Porous Self-Protonating Spiropyran-Based NIPAAm Gels with Improved Reswelling Kinetics. J. Mater. Sci. 2016, 51, 1392-1399.

(59) Kullmann, M.; Ruetzel, S.; Buback, J.; Nuernberger, P.; Brixner, T. Reaction Dynamics of a Molecular Switch Unveiled by Coherent TwoDimensional Electronic Spectroscopy. J. Am. Chem. Soc. 2011, 133, 13074-13080.

(60) Hobley, J.; Malatesta, V.; Giroldini, W.; Stringo, W. $\pi$-Cloud and Non-Bonding or H-Bond Connectivities in Photochromic Spiropyrans and Their Merocyanines Sensed by ${ }^{13} \mathrm{C}$ Deuterium Isotope Shifts. Phys. Chem. Chem. Phys. 2000, 2, 53-56.

(61) Ramamurthy, V.; Schanze, K. S. Photochemistry of Organic Molecules in Isotropic and Anisotropic Media; Marcel Dekker, Inc.: New York, 2003.

(62) Nuernberger, P.; Ruetzel, S.; Brixner, T. Multidimensional Electronic Spectroscopy of Photochemical Reactions. Angew. Chem., Int. Ed. 2015, 54, 11368-11386. 